\title{
Transcriptome sequencing and analysis of Plasmodium gallinaceum reveals polymorphisms and selection on the apical membrane antigen-1
}

Elvin J Lauron ${ }^{1 *}$, Khouanchy S Oakgrove ${ }^{1}$, Lisa A Tell ${ }^{2}$, Kevin Biskar ${ }^{1}$, Scott W Roy ${ }^{1}$ and Ravinder NM Sehgal ${ }^{1}$

\begin{abstract}
Background: Plasmodium erythrocyte invasion genes play a key role in malaria parasite transmission, host-specificity and immuno-evasion. However, the evolution of the genes responsible remains understudied. Investigating these genes in avian malaria parasites, where diversity is particularly high, offers new insights into the processes that confer malaria pathogenesis. These parasites can pose a significant threat to birds and since birds play crucial ecological roles they serve as important models for disease dynamics. Comprehensive knowledge of the genetic factors involved in avian malaria parasite invasion is lacking and has been hampered by difficulties in obtaining nuclear data from avian malaria parasites. Thus the first Illumina-based de novo transcriptome sequencing and analysis of the chicken parasite Plasmodium gallinaceum was performed to assess the evolution of essential Plasmodium genes.

Methods: White leghorn chickens were inoculated intravenously with erythrocytes containing P. gallinaceum. cDNA libraries were prepared from RNA extracts collected from infected chick blood and sequencing was run on the HiSeq2000 platform. Orthologues identified by transcriptome sequencing were characterized using phylogenetic, ab initio protein modelling and comparative and population-based methods.

Results: Analysis of the transcriptome identified several orthologues required for intra-erythrocytic survival and erythrocyte invasion, including the rhoptry neck protein 2 (RON2) and the apical membrane antigen-1 (AMA-1). Ama-1 of avian malaria parasites exhibits high levels of genetic diversity and evolves under positive diversifying selection, ostensibly due to protective host immune responses.

Conclusion: Erythrocyte invasion by Plasmodium parasites require AMA-1 and RON2 interactions. AMA-1 and RON2 of $P$. gallinaceum are evolutionarily and structurally conserved, suggesting that these proteins may play essential roles for avian malaria parasites to invade host erythrocytes. In addition, host-driven selection presumably results in the high levels of genetic variation found in ama-1 of avian Plasmodium species. These findings have implications for investigating avian malaria epidemiology and population dynamics. Moreover, this work highlights the P. gallinaceum transcriptome as an important public resource for investigating the diversity and evolution of essential Plasmodium genes.
\end{abstract}

Keywords: Avian malaria, Transcriptome, Apical membrane antigen I, Synonymous, Non-synonymous, Polymorphism

\footnotetext{
* Correspondence: elauron@mail.sfsu.edu

'Department of Biology, San Francisco State University, San Francisco, CA 94132, USA

Full list of author information is available at the end of the article
} 


\section{Background}

Immuno-evasion is likely a major factor that influences the evolution of Plasmodium parasites, the causative agent of malaria [1]. Parasites with antigenic diversity may have frequency-dependent advantages and as a result evolve under strong positive/diversifying selection [2]. The genetic diversity maintained by positive selection in target malaria antigens poses a major problem in the development of effective malaria vaccines [3,4]. In general, most genes that encode antigens of Plasmodium parasites are highly polymorphic and encode proteins that are important targets for host protective antibody responses [5]. Indeed, polymorphisms in the circumsporozoite protein, a cell surface protein required for sporozoites to attach and invade target cells, appear to be maintained by selective pressures exerted via host protective immune responses [6,7]. Evidence for positive selection has also been reported for the Plasmodium surface proteins DBP (Duffy-binding protein), EBA-175 (erythrocyte-binding antigen 175) and a large number of other antigens [8].

Polymorphisms maintained by selective pressures within erythrocyte-binding ligands may alter the host receptorspecificity of Plasmodium parasites [3,9,10]. In Plasmodium parasites that infect multiple host species through host-switching events, e.g., avian malaria species, such polymorphisms may contribute to a broad host-specificity range [11]. The host-specificity of avian malaria parasites is diverse: some parasites can infect hosts from multiple families or even multiple orders; others are restricted to a single avian family or even species [12-14]. Therefore, avian Plasmodium parasites provide an exceptional model for studying host specificity and host-parasite co-evolutionary dynamics in natural populations $[15,16]$.

Host-parasite co-evolutionary relationships are thought to maintain genetic diversity in both host and parasite populations [17]. Indeed, there is evidence for parasitedriven diversifying selection in avian hosts [18-20]. However, little is known regarding host-driven selection in avian Plasmodium parasites. This is largely due to the difficulties of identifying and obtaining data on nuclear genes: since erythrocytes are nucleated in bird hosts, it is hard to isolate parasite DNA/RNA from the much more abundant host material [21]. Therefore, Plasmodium gallinaceum, a parasite of the domestic chicken (Gallus gallus), was chosen to perform transcriptome sequencing and analysis in this study since it is relatively easy to propagate in chickens and generating high parasitemia is readily achieved with this strain.

Plasmodium gallinaceum has been an important model for understanding cellular biological mechanisms involved in malaria parasite transmission [22-24], and can yield insight applicable to Plasmodium falciparum [25], as $P$. falciparum shares high similarity with the genome of $P$. gallinaceum. This is supported by phylogenetic evidence [26-31] and biochemical data that functionally confirm the evolutionary relationships [25]. Here, the goal was to identify orthologues of essential and well-characterized P. falciparum genes from the P. gallinaceum transcriptome; some of these include the long chain fatty acid elongation enzyme (ELO3), LCCL domain-containing protein $(C C p 2)$, and serine hydroxymethyltransferase (SHMT).

SHMT is highly upregulated throughout the intraerythrocytic development stages [32] and plays an indispensable role in the de novo pyrimidine biosynthesis pathway in Plasmodium parasites; the essentiality of SHMT has been confirmed through SHMT-knockout parasites [33]. ELO3 and CCp2 also play essential roles during intra-erythrocytic development and are specifically required for Plasmodium gametocytogenesis, as demonstrated by transposon-mediated insertional mutagenesis [34]. In addition, two orthologues that are essential for erythrocytic invasion, AMA-1 (a major malaria vaccine candidate) and RON2 (the AMA-1 receptor) were characterized in this study.

Plasmodium invasion of erythrocytes can be blocked by antibody-mediated inhibition of AMA-1-RON2 interactions [35-37], and the vaccine potential of AMA-1 has been well demonstrated in various animal models [38-40]. In spite of these promising results, different isolates of the same species exhibit polymorphisms in ama1 that may allow parasites to avoid inhibitory effects of natural anti-AMA1 antibodies produced by host protective immune responses [41]. Moreover, natural immune responses to AMA-1 have also revealed polymorphic B and $\mathrm{T}$ cell epitopes within AMA-1 that are maintained by positive selection [42,43]. Given that AMA-1 is a highly polymorphic antigen that is unique to apicomplexan parasites $[44,45]$, the level of diversity and selection on avian Plasmodium ama-1 was evaluated. The results of this study have implications for studying erythrocyte invasion, host immune responses and the population genetics and epidemiology of avian malaria parasites.

\section{Methods}

\section{Infection of chickens}

A total of seven White Leghorn chickens were hatched at the animal facility of the University of California, Davis, and were kept in cages with water and feed. After six days, six chicks were inoculated intravenously with erythrocytes containing P. gallinaceum. One chick was inoculated with saline solution as a negative control. Blood samples were obtained from the jugular vein seven days post infection and subsequently every two to three days. Blood samples were stored in TRIzol $^{\circ}$ RNA Isolation Reagent (Life Technologies, USA) and were 
immediately flash frozen in an ethanol-dry ice bath, or used for blood smear examination. Blood smears were stained with Giemsa, and the infection status was verified by microscopy and PCR amplification of the cytochrome $b$ gene [46].

\section{Generation of CDNA libraries, sequencing and data analysis of the Plasmodium gallinaceum blood stages}

Total RNA was prepared directly from the frozen samples of parasitized erythrocytes. RNA was extracted using Phase Lock Gel and ethanol precipitation methods [47]. The RNA quality was checked on the Bioanalyzer 2100 (Agilent Technologies Inc., USA). cDNA libraries were prepared from RNA extracts and sequenced at the qb3 Genomics Sequencing Laboratory at the University of California, Berkeley, USA as follows: rRNA was depleted from RNA extracts using Ribo-Zero ${ }^{\mathrm{Tm}}$ (Epicentre, USA) prior to generating cDNA libraries using TruSeq (Illumina Inc, USA). Sequencing was run in one lane as paired-end reads of 100 base pairs (bp) on the HiSeq2000 platform. The quality of all Illumina reads was assessed with FastQC [48]. Overall, the sequence reads were of good quality (average quality score of 38 per read). Seventy-five per cent of the sequence reads had a quality score $\geq 30$. Thus, no quality trimming was required nor performed, so as to minimize loss of the dataset. Blat/ Bowtie $[49,50]$ query of the Illumina reads against the G. gallus (chicken) genome was run to remove chicken sequences. Adapters were removed and the remaining paired-end reads were used for the de novo reconstruction of the $P$. gallinaceum transcriptome using Trinity [51]. To identify P. gallinaceum protein-coding transcripts involved in erythrocyte invasion, intra-erythrocytic survival and gametocytogenesis, Tblastn of the P. gallinaceum transcriptome against the $P$. falciparum transcriptome was performed using Geneious 7.0.4. An E-value cut-off of 1e-10 was chosen for identifying putative orthologues. The $P$. falciparum transcriptome was downloaded from PlasmoDB [52].

\section{Sample collection}

Plasmodium lucens isolates used in this study came from blood samples collected from a single species, the Olive Sunbird (Cyanomitra olivacea), in Cameroon during the period 2005 to 2007 [46]. Plasmodium globularis was isolated from blood samples collected from the Yellowwhiskered Greenbul (Andropadus latirostris) in Ghana, 2007 [53]. Plasmodium megaglobularis isolates came from blood samples collected from the Olive-bellied Sunbird (Cinnyris chloropygius) in Cameroon during 1990 [53]. Plasmodium lineage spp. PV16 isolates were from blood samples collected from the Olive Sunbird in Cameroon during 2005 [14]. Plasmodium homopolare isolates were collected from various birds in China Creek
County Park, California, USA (Additional file 1) during 2011 to 2013 [54]. All birds were caught with mist-nets and banded. Blood samples were collected from the brachial vein and samples were stored in lysis buffer $(10 \mathrm{mM}$ Tris-HCL pH 8.0, 100 mM EDTA, 2\% SDS).

\section{PCR amplification and DNA sequencing}

DNA was extracted from whole blood following a DNeasy kit protocol (Qiagen, USA). Identification of avian Plasmodium species was based on PCR assays and sequences of the cytochrome $b$ gene [55]. The P. gallinaceum ama-1 coding sequence was identified using the $P$. gallinaceum RNA-seq data, and ama-1 domain I primers were designed based on conserved regions among P. gallinaceum and other mammalian Plasmodium species. A nested PCR was used to amplify the hypervariable domain I region of ama-1 corresponding to 444-906 bp or 271-732 bp according to P. falciparum ama-1 or P. gallinaceum ama-1, respectively. The following primers were used for the first round of amplification: $P g_{-} A M A 1 \mathrm{~F} 1$ (GATTTAGGTGAAGATGCAGAA GT) and $P g \_A M A 1 R 1$ (TTAATTAAACATGTTGGTTT TACAT). The amplification conditions were as follows, first, $4 \mathrm{~min}$ at $94^{\circ} \mathrm{C}$, followed by 20 cycles with $0.5 \mathrm{~min}$ of denaturation at $94^{\circ} \mathrm{C}$, annealing at $50^{\circ} \mathrm{C}$ for $1 \mathrm{~min}$, and elongation at $72^{\circ} \mathrm{C}$ for $1.2 \mathrm{~min}$. After 20 cycles, a final elongation step at $72^{\circ} \mathrm{C}$ for 5 min was carried out. The amplified products of $785 \mathrm{bp}$ were used for the second round of amplification with the following primers: $P g \_$AMA1F2 (ATGTCCAGTTTTTGGAAAAGGTAT) and $P g \_A M A 1 R 2$ (CCATCAACCCATAAT CCAAATTT). The second round amplification conditions were as follows first, $1 \mathrm{~min}$ at $94^{\circ} \mathrm{C}$, followed by 40 cycles with $0.5 \mathrm{~min}$ of denaturation at $94^{\circ} \mathrm{C}$, annealing at $53^{\circ} \mathrm{C}$ for $1 \mathrm{~min}$, and elongation at $72^{\circ} \mathrm{C}$ for $0.7 \mathrm{~min}$. After 40 cycles, a final elongation step at $72^{\circ} \mathrm{C}$ for $5 \mathrm{~min}$ was carried out. The amplified products of 500 bp were run out on a 1.8\% agarose gel using $1 \times$ TBE, and visualized by ethidium bromide staining under ultraviolet light. Resulting amplicons were purified using ExoSap (following manufacture's instructions, USB Corp, USA) and sequenced by ElimBio (Hayward, USA), see Additional file 2 and Additional file 3 for accession numbers. Several attempts to amplify domain II and III were unsuccessful, which may have been due to the low GC content in these regions and the difficulty in designing highly specific primers.

\section{Phylogenetic analyses}

DNA sequences were analysed using Geneious v7.0.4 created by Biomatters. Sequences were aligned using MUSCLE with Seaview software [56]. DNA sequences were translated and adjusted in Mesquite v2.75 [57]. Phylogenetic relationships were inferred using maximum likelihood (ML), as implemented in RAxML [58]. For 
ML, Modeltest v3.7 [59] was used to determine the most appropriate nucleotide substitution model based on the Akaike Information Criterion (AIC) [60]. ML methods for the ama-1 and SHMT genes were implemented using the GTR + I + G model that permits rate variations in all six base substitution types for unequal base composition, invariable sites and among site rate variation. ML methods for the RON2, ELO3, CCp2 genes were implemented using the GTR + G model. A thorough ML search was performed along with 10,000 bootstrap inferences.

\section{Protein structure modelling}

Three-dimensional (3D) models representing tertiary protein structures of AMA-1, domain I of AMA-1 alone, and RON2 was generated using an ab initio approach with the iterative implementation of the threading assembly refinement (I-TASSER) method [61,62]. The accuracy of the 3D models was assessed based on the confidence $(\mathrm{C})$ score and the template modelling (TM) score. The quality of the top-ranked 3D models, measured by LGscore and MaxSub values, was further assessed using protein quality predictor ProQ [63]. 3D models with an LGscore greater than 2.5 are considered very good models, where as values above 4 indicate extremely good models. 3D models with MaxSub values above 0.1 are considered fairly good models, whereas values above 0.5 indicate very good models. Secondary structures of AMA-1 or domain I of AMA-1 alone and RON2 were determined by PSIPRED v3.3 [64].

\section{Statistical analyses of genetic diversity}

A total of 51 P. lucens ama-1 sequences consisting of 12 different haplotypes were compared with 49 P. falciparum ama-1 sequences. The McDonald-Kreitman test [65] was performed on domain I of $a m a-1$ to determine whether this region is evolving under selection. The $d_{\mathrm{N}} /$ $d_{\mathrm{S}}$ (non-synonymous substitutions per non-synonymous sites divided by synonymous substitutions per synonymous sites) ratio was evaluated using a sliding window method to investigate selection across the region, as implemented in DNAsp v5.10 [66]. Significant differences between $d_{\mathrm{N}}$ and $d_{\mathrm{S}}$ were evaluated for the entire region of domain I and for regions with high $d_{\mathrm{N}} / d_{\mathrm{S}}$ ratios using the Nei and Gojobori method with the Jukes and Cantor correction, and a one-tailed Z-test with 1,000 bootstrap pseudosamples, as implemented in MEGA v5.2.2 [67]. Between-species divergence $(K)$ using Jukes and Cantor correction was calculated with MEGA (see Additional file 4 and Additional file 5). The nucleotide diversity $(\pi)$ across domain I of P. lucens ama-1 was also evaluated using a sliding window method.

Tajima's test was performed to determine if sequences departed significantly from neutral variation patterns. With Tajima's test, departure from neutrality is measured by differences between $\pi$ and the nucleotide diversity expected under neutrality $(\theta) . \pi$ is expected to increase above that of $\theta$ as a result of a rare allele being selected and maintained at intermediate frequencies under positive selection. Thus, a positive test statistic $(D)$ value under positive diversifying selection is expected $[68,69]$. $\mathrm{Fu}$ and Li's test was also performed using $P$. gallinaceum as outgroup to determine whether mutations are selectively neutral. Similarly, a positive value of $D^{*}$ and $F^{*}$ under positive diversifying selection is expected. When comparing estimates of $\theta$ based on singleton sites to that derived from the $D^{*}$ or $F^{*}$ index, an excess of intermediate frequency polymorphisms and lower number of singleton sites makes the statistics values positive $[69,70]$. To check for clustering, a metric multidimensional scaling analysis was performed in $\mathrm{R}$ using the bios $2 \mathrm{mds}$ package.

\section{Results}

Transcriptome sequencing

A total of $100 \mathrm{~Gb}$ comprising of $220 \mathrm{M} 100$ nucleotide (nt) paired-end sequencing read was obtained. Sixtythree percent of the total sequence reads obtained were removed after running a Bowtie query against the $G$. gallus genome. The remaining $82 \mathrm{M}$ sequence-read pairs were assembled de novo using Trinity. Long open reading frames (ORFs) within the assembled transcriptome were identified. These putative coding sequences (CDS) were compared to the $P$. falciparum (isolate 3D7) transcriptome. Eighty-one per cent of P. falciparum CDS sequences had a significant BLAST hit within the P. gallinaceum transcriptome, suggesting that the $P$. gallinaceum transcriptome obtained was fairly complete. The size distribution for the CDS that showed homology to P. falciparum CDS is shown in Additional file 6 .

\section{Identification and phylogenetic analysis of genes essential for intra-erythrocytic stage survival, and gametocytogenesis}

A full-length cDNA sequence encoding an orthologue of SHMT in P. gallinaceum, with an $84 \%$ amino acid sequence identity in a pairwise comparison to $P$. falciparum SHMT, was identified. The translated SHMT sequences of all analysed Plasmodium species resulted in proteins with identical lengths of 442 amino acids. Twelve cysteines were present in $P$. gallinaceum SHMT, eight of which were conserved in position.

In addition, ELO3 and $C C p 2$ were also identified as orthologues in P. gallinaceum. The full-length cDNA sequence was obtained for ELO3 and a partial cDNA sequence was obtained for $C C p 2$. The 5' exon sequence of $C C p 2$ was missing approximately $650 \mathrm{bp}$. The resulting coding sequences of ELO3 and $C C p 2$ are 1,920 and $4,201 \mathrm{bp}$, respectively. DNA sequences were translated and aligned; the resulting amino acid sequences showed 
79 and $74 \%$ identity in pairwise comparisons to P. falciparum ELO3 and CCp2, respectively. The P. gallinaceum CCp2 amino acid sequence (1,348 amino acids) that was analysed contains 17 cysteines, all of which were conserved between mammalian Plasmodium species. The translated P. gallinaceum ELO3 full-length transcript sequence resulted in a protein of 521 amino acids and was approximately 121 amino acids shorter than the $P$. falciparum ELO3 protein. Phylogenetic analyses suggested that these essential orthologues in P. gallinaceum are most similar to $P$. falciparum (as compared to other mammalian Plasmodium species) (Figure 1A-C). The high degree of conservation suggests that these orthologues may also play important roles during the intra-erythrocytic stages of $P$. gallinaceum.

\section{Identification and phylogenetic analysis of ama-1 and the} ama-1 receptor RON2 in Plasmodium gallinaceum

The coding region of $P$. gallinaceum ama-1 was $1,692 \mathrm{bp}$ with an $\mathrm{A}+\mathrm{T}$ content $(72 \%)$ greater than $P$. falciparum (around 70\%). The translated protein sequence was 556 amino acids long, shared $55 \%$ amino acid identity to $P$. falciparum ama-1, and contains 17 cysteines. All 16 cysteines within the three cysteine-rich domains of AMA-1

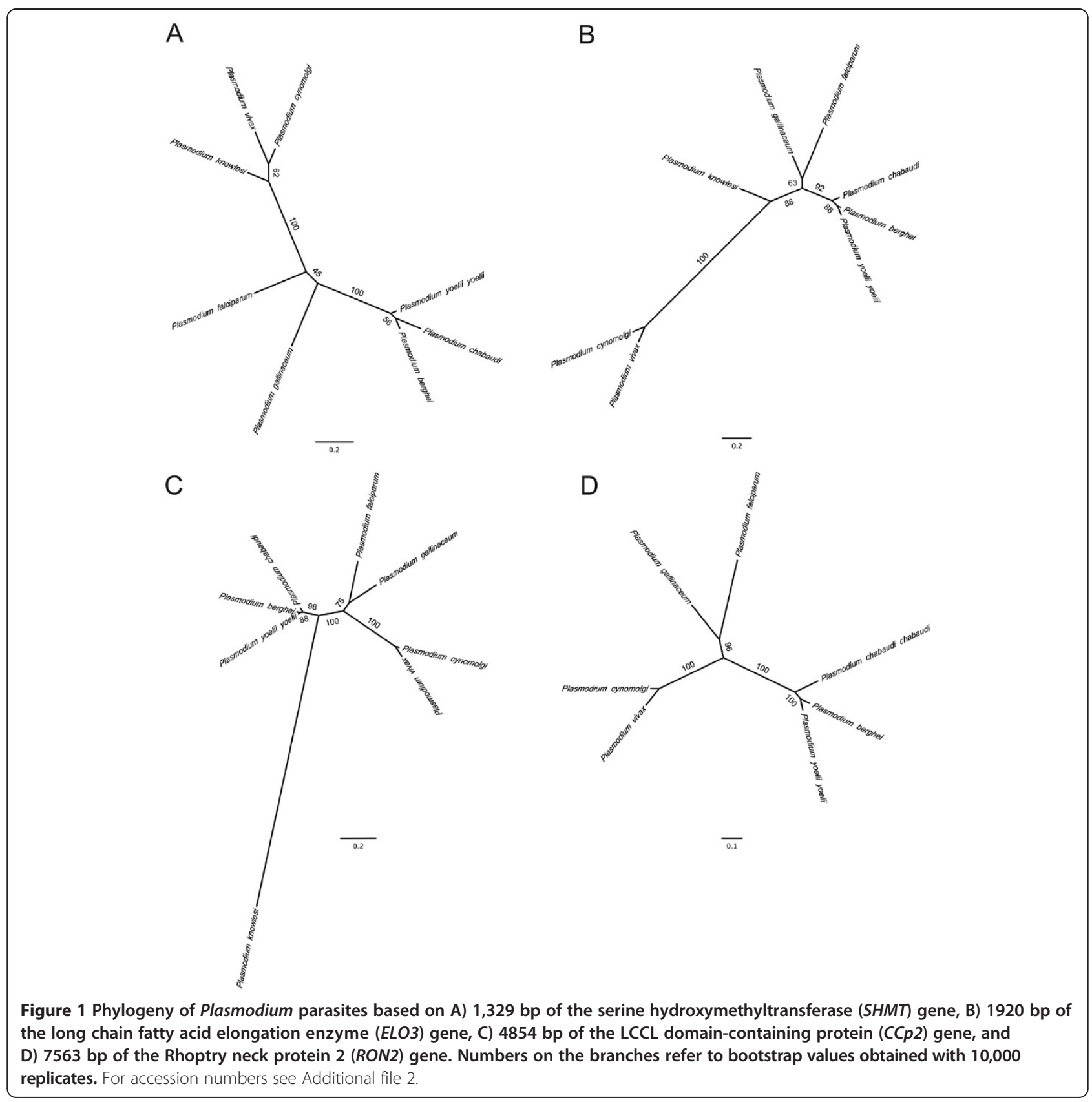


were conserved in number and position when the aligned protein sequences of individual domains were analysed, with the exception of domain III. Domain III contains six cysteine residues [71,72], which were present in both $P$. gallinaceum and P. falciparum ama-1. However, domain III of P. gallinaceum AMA-1 contained five amino acid deletions between positions 465-471 (relative to $P$. falciparum AMA-1). Therefore, the position of cysteines and the number of amino acids in domain III varied slightly between $P$. gallinaceum and P. falciparum. Phylogenetic analysis of ama-1 revealed $P$. gallinaceum ama- 1 as significantly divergent from all mammalian Plasmodium species analysed (Figure 2). A metric multidimensional scaling (MDS) analysis was performed to complement the phylogeny and to visualize the evolutionary trajectories of ama-1 on a low dimensional space. Principal component analysis (PCA) plots showed clustering consistent with that of the ama-1 phylogeny (Figure 2). Phylogenetic and metric multidimensional scaling analysis of all ama-1 sequences compared in this study placed avian Plasmodium parasites into a strongly supported monophyletic clade and cluster (Additional file 7).

In addition to identifying AMA-1 in P. gallinaceum, a full-length cDNA sequence encoding a version of $P$. gallinaceum RON2 was identified. P. gallinaceum RON2 was truncated at the $\mathrm{N}$ terminus by approximately 620 amino acids, in comparison to the translated full-length cDNA sequence of $P$. falciparum RON2. The coding sequence of $P$. gallinaceum RON2 was 4,641 bp and encodes a protein of 1545 amino acids with $71 \%$ identity to $P$. falciparum RON2. Two conserved cysteines that are required for RON2 to bind the AMA-1 pocket [73] were conserved in P. gallinaceum RON2 (Figure 3). A phylogenetic analyses of RON2 groups $P$. gallinaceum with $P$. falciparum (Figure 1D).

\section{ama-1 polymorphisms in avian Plasmodium field isolates}

The entire ama-1 domain I region consisting of $468 \mathrm{bp}$ was sequenced and analysed from a total of $51 \mathrm{P}$. lucens isolates collected from African rainforest birds. A sliding window analysis of $\pi$ using a window of $30 \mathrm{bp}$ moved in steps of nine sites reveals polymorphisms across the entire region of domain I (Figure 4A). The region 787$816 \mathrm{bp}$ appears to be the most polymorphic region in domain I of $P$. lucens ama-1. This region corresponds to the naturally immunogenic $\mathrm{T}$ cell epitope located within residues 259-271 of $P$. falciparum AMA-1, which was also reported to be polymorphic [42]. Three-hundred

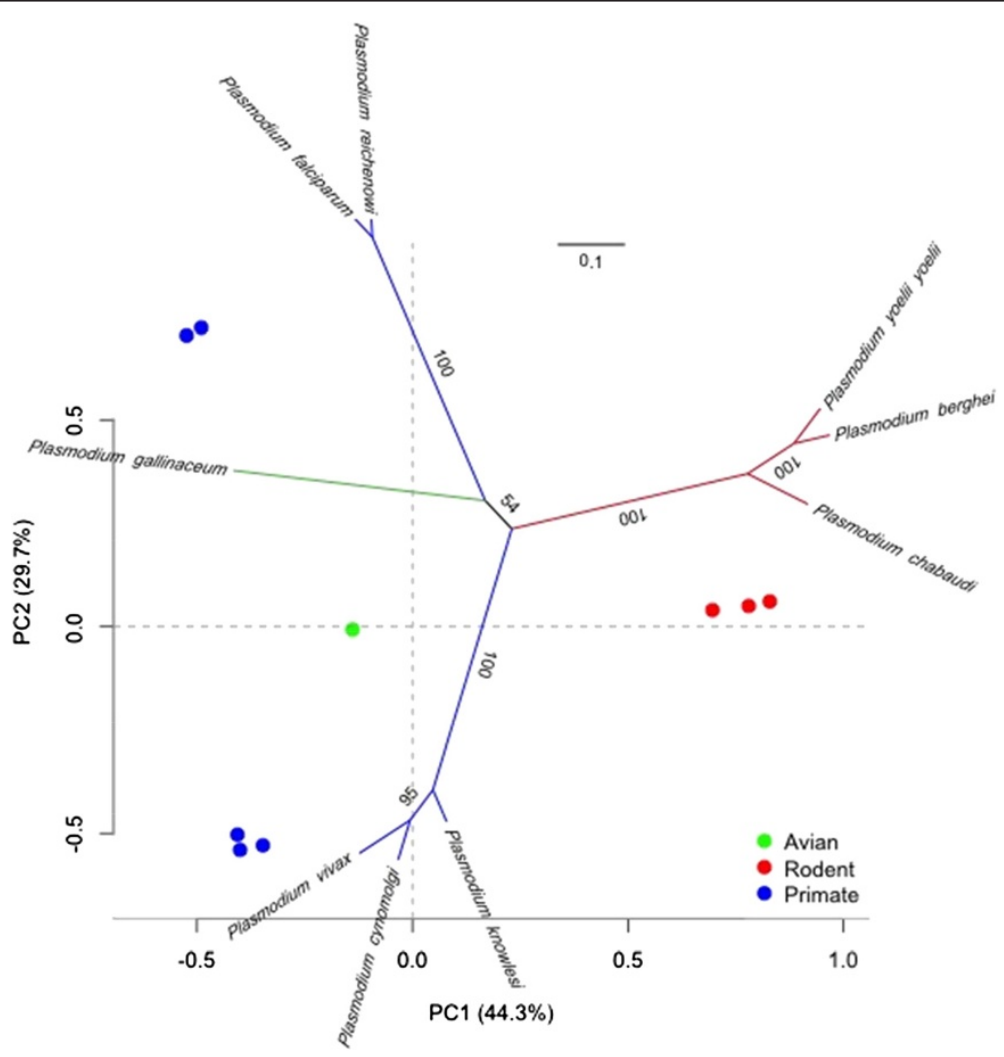

Figure 2 Phylogeny and metric multidimensional scaling of Plasmodium parasites using ama-1. A matrix of distances ( $p$-distance) were generated from aligned ama-1 sequences. The distance matrix was used to calculate principal components and is represented by metric multidimensional scaling (MDS). For graphical purposes, the phylogeny was superimposed onto a PCA plot to visualize sequence space. 


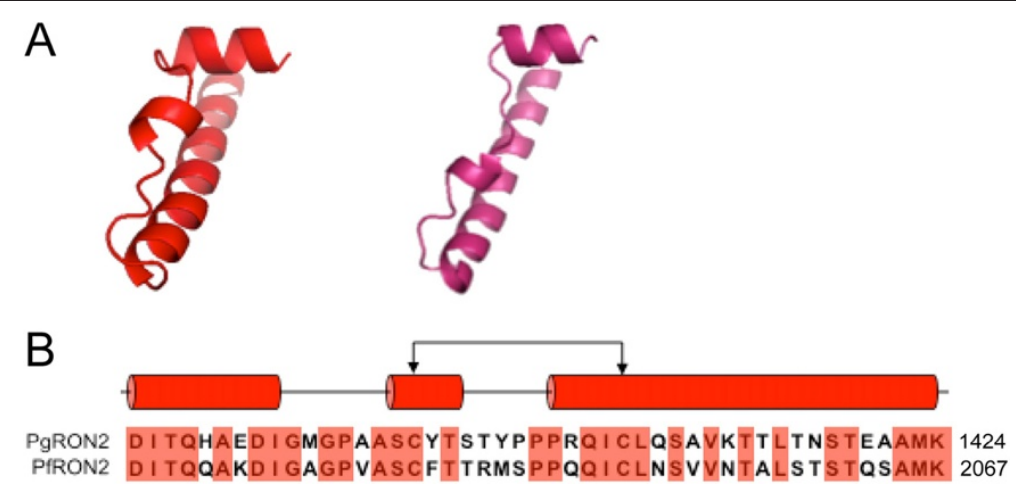

Figure 3 Three-dimensional models of the avian Plasmodium RON2 protein. A) Stereo views of the C-terminus of $P$. gallinaceum RON2 (left) and $P$. falciparum RON2 (right). B) Sequence alignment of $P$. gallinaceum and $P$. falciparum RON2 are shown with the secondary structure of the corresponding amino acid regions above the alignment. Helices are colored red. The line with connecting arrows indicates disulfide bonds. Conserved amino acids are highlighted in red.

and eighty-seven monomorphic sites and 81 polymorphic sites were detected in domain I of P. lucens ama-1. Three polymorphic sites at positions 116, 138 and 205 exhibited three different nucleotides, whereas the remaining sites had only two. A total of 77 mutations were detected, 27 of which were synonymous and 50 of which were non-synonymous. $\pi$ for all 51 sequences analysed was $0.043237 \pm 0.005210 \mathrm{SD}$, which is more polymorphic than previously reported $\pi$ (0.01361$0.01764)$ for $P$. falciparum isolates [42,74].

An alignment of the translated sequences revealed three additional amino acid residues (Glu-Phe-X) positioned near hydrophobic amino acids that line the hydrophobic trough of domain I (Additional file 8). The additional amino acids are located between residues 184-185 relative to P. falciparum AMA-1. Considering that it is unknown

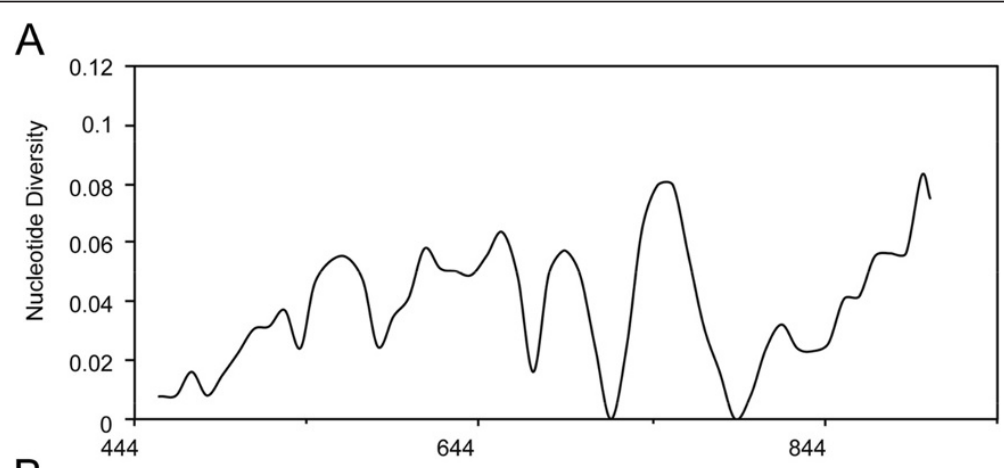

B

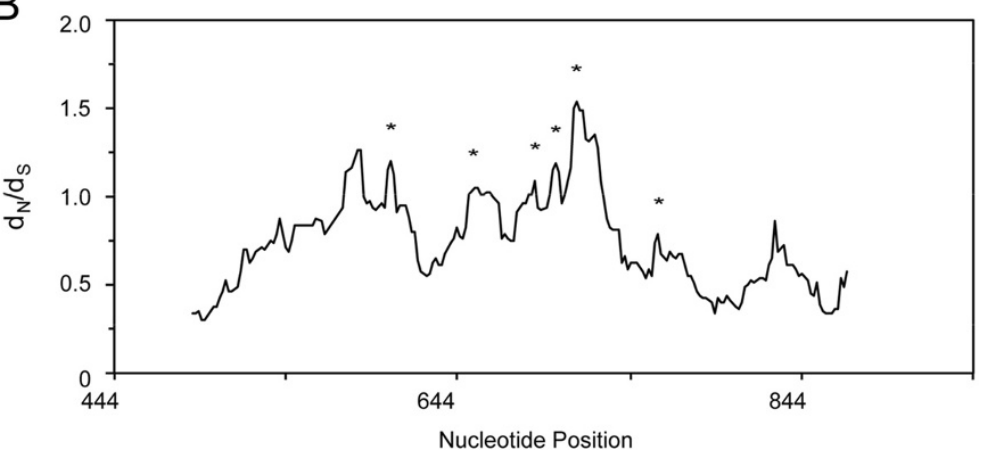

Figure 4 Sliding window plot of A) $\pi$ and B) $d_{\mathbf{N}} / d_{\mathbf{S}}$ for domain I of Plasmodium lucens ama-1. Nucleotide positions are relative to the P. falciparum 3D7 line sequence. The window length is $30 \mathrm{bp}$ with a step size of $9 \mathrm{bp}$ for the sliding window analysis of $\pi$. The window length is $90 \mathrm{bp}$ with a step size of $3 \mathrm{bp}$ for the sliding window analysis of $d_{N} / d_{\mathrm{S}}$. Asterisks indicate regions with a significant excess of non-synonymous substitutions. 
whether the tertiary structure of AMA-1 in avian Plasmodium species contains a hydrophobic trough, a 3D model of the full-length $P$. gallinaceum AMA-1 was generated. Tertiary structure-based analysis of the resulting 3D model was found to be satisfactory (LGscore $=3$, Max$\mathrm{Sub}=0.3$ ). Conserved hydrophobic amino acid residues that line the hydrophobic trough, according to P. falciparum AMA-1 positions found by Bai et al. [75], were highlighted in green. All highlighted residues (111, 125, 132, 144, 299, 313 relative to P. gallinaceum AMA-1) also appeared to reside in a small yet extended pocket of $P$. gallinaceum AMA-1 (Figure 5A), with the exception of residues 193 and 194. 3D models for the AMA-1 domain I of P. lucens and P. falciparum were also generated to visually compare intraspecific polymorphisms (Figure 5B).
To determine whether these polymorphisms and additional amino acids are present among other avian Plasmodium species, domain I of ama-1 from $28 P$. homopolare (a newly identified host-generalist), three P. megaglobularis (host-generalist), three Plasmodium lineage spp. PV16, and two P. globularis (host-specialist) isolates $[14,54]$ were sequenced. Between-species divergence $(K)$ ranged 0.062-0.349 (Additional file 4), approximately two to three-fold greater than $\mathrm{K}$ calculated for cytochrome $b$ (0.030-0.103). Attempts to sequence domain I from other avian species, including Plasmodium relictum (GRW11 and SGS1) isolates were unsuccessful, likely due to low parasitaemia or parasite genomic DNA concentrations. Interestingly, no intraspecific polymorphisms were observed. However, additional amino acids in domain I

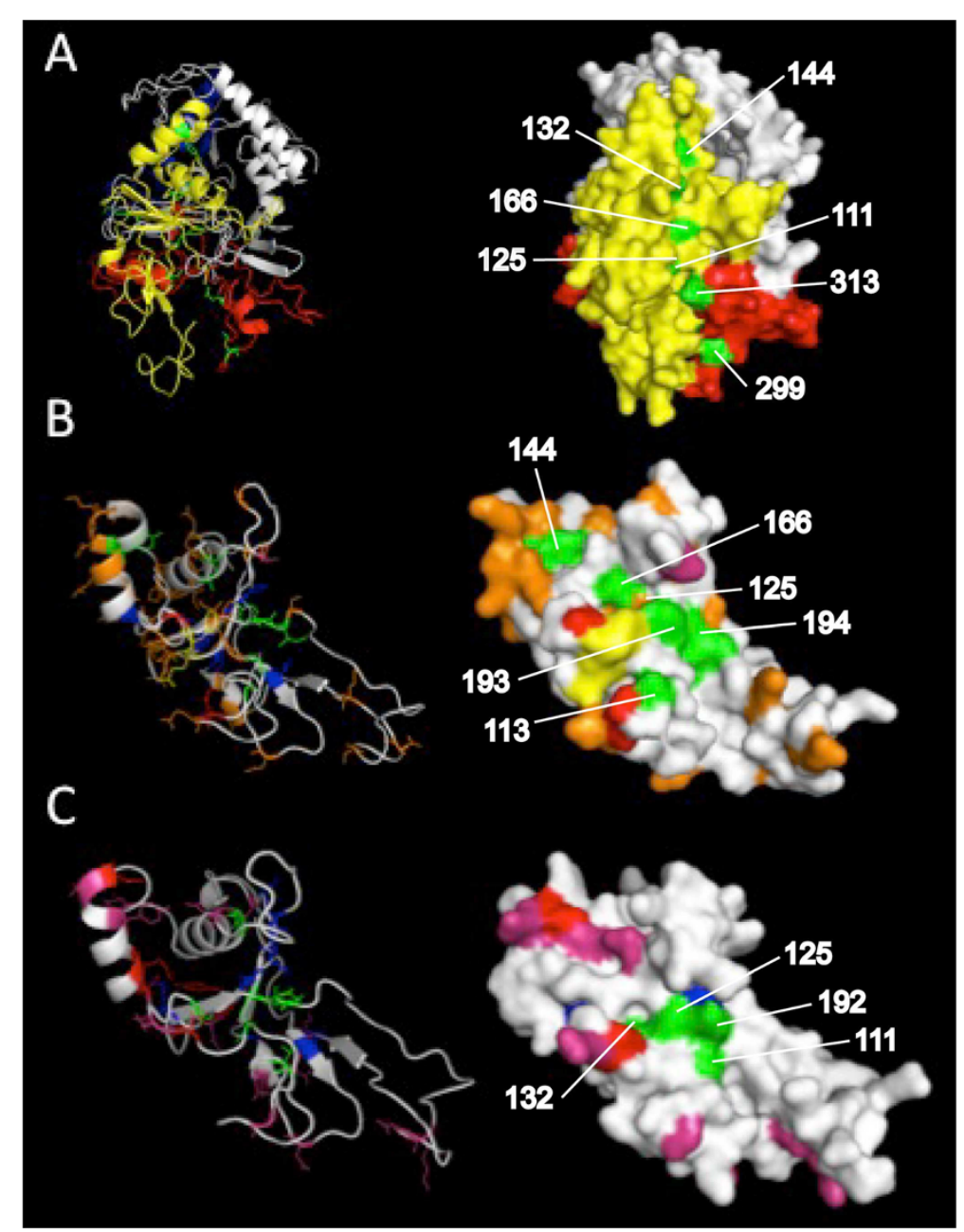

Figure 5 Three-dimensional models of the avian Plasmodium AMA-1 protein. The ab initio-generated models are based on the A) 556 aa sequence of $P$. gallinaceum AMA-1, B) 155 aa residues in AMA-1 domain I of $P$. lucens, and C) 152 aa residues in AMA-1 domain I of $P$. falciparum. Both stereo (left) and surface (right) views are shown. Domain I, II and III of $P$. gallinaceum AMA-1 are coloured yellow, red and blue, respectively. Conserved hydrophobic residues that line the putative hydrophobic trough are labelled and highlighted in green. Plasmodium lucens and $P$. falciparum AMA-1 models are coloured as follows: conserved hydrophobic residues are shown in blue, highly polymorphic residues are shown in red, high-frequency dimorphisms are shown in pink, low-frequency dimorphisms are shown in orange. The observed amino acid insertions in domain I of P. lucens AMA-1 are shown in yellow. 
were present in all field-caught avian Plasmodium species included in this study. Similar to $P$. lucens, domain I of $P$. megaglobularis, lineage PV16, and P. globularis AMA-1 sequences contain three additional amino acids (Glu-Phe-X) between residues 184-185, whereas the domain I of $P$. homopolare AMA-1 contains two amino acid (Arg-Asp) insertions between residues 187-188 (Additional file 8). All additional amino acids observed were located within or near hydrophobic amino acids that line the hydrophobic pocket.

\section{Comparison of Plasmodium lucens ama-1 and Plasmodium falciparum ama-1 sequences}

Forty-nine $P$. falciparum ama-1 sequences were compared with 51 P. lucens ama- 1 sequences in an alignment covering the entire domain I region. There were a total of 120 fixed nucleotide differences between the species. Of these differences, 33\% (39) were synonymous and $67 \%$ were (81) non-synonymous. There were a total of 121 polymorphic sites within-species, of which $22 \%$ (27) sites were synonymous and 78\% (94) were nonsynonymous. A McDonald-Kreitman test with domain I sequences detected significant departure from neutrality in the $P$. lucens ama-1 domain I region (Neutrality Index $(\mathrm{NI})=1.676, \mathrm{P}=0.07$; NI with Jukes and Cantor correction $=2.035, \mathrm{P}=0.009$ ), suggesting that polymorphisms at the domain I are maintained under positive diversifying selection.

A $d_{\mathrm{N}} / d_{\mathrm{S}}$ analysis of the entire domain did not detect significant differences between non-synonymous and synonymous changes. To determine if regions with high $d_{\mathrm{N}} / d_{\mathrm{S}}$ ratios are under selection, a sliding-window analysis (90 bp with a step size of three bases) of $d_{\mathrm{N}} / d_{\mathrm{S}}$ was conducted. Significant difference between $d_{\mathrm{N}}$ and $d_{\mathrm{S}}$ was detected throughout domain I (at the midpoint nt position of region 543-650, $d_{\mathrm{N}} / d_{\mathrm{S}}=3.51, \mathrm{P}<0.0005$; mid point $\mathrm{nt}$ position of region $609-698, d_{\mathrm{N}} / d_{\mathrm{S}}=1.90, \mathrm{P}<0.05$; mid point nt position of region $645-735, d_{\mathrm{N}} / d_{\mathrm{S}}=1.97, \mathrm{P}<$ 0.05 ; mid point nt position of region $657-746, d_{\mathrm{N}} / d_{\mathrm{S}}=$ $1.66, \mathrm{P}=0.05$; mid point $\mathrm{nt}$ position of region 669-758, $d_{\mathrm{N}} / d_{\mathrm{S}}=2.01, \mathrm{P}<0.05$ ) (Figure $4 \mathrm{~B}$ ), suggesting that these regions are under positive diversifying selection.

No significant departure from the neutral expectation was detected using Tajima's $D(D=-0.12236, \mathrm{P}>0.10)$. Similar results were obtained for the $\mathrm{Fu}$ and $\mathrm{Li} D^{*}$ (1.32144, $\mathrm{P}>0.10)$, whereas the $F^{*}$ value of 1.79767 was significant with $\mathrm{P}<0.02$. Sliding-window analysis with a window of $30 \mathrm{bp}$ and a step size of nine bases did not detect significantly low or high statistics values for all neutrality tests along the domain I region of ama-1. To ensure that the true level of variation is not obscured from choosing too small of a window, the slidingwindow analysis with a window of $90 \mathrm{bp}$ and a step size of three bases was performed. Significantly high F* values were observed between $658-786$ bp and 718$831 \mathrm{bp}$ (Figure 6). These results of the population-based methods also support the findings from comparing $d_{\mathrm{N}}$ to $d_{\mathrm{S}}$, and provide additional evidence that the domain I region of $P$. lucens ama-1 is under positive diversifying selection.

\section{Discussion}

Assessing the genetic diversity and selection in erythrocyte invasion genes of avian malaria parasites may provide insight on the population and the transmission dynamics of malaria. Higher rates of malaria transmission are expected to occur in areas with high parasite diversity [76]. This prediction is supported by the high levels of diversity in nuclear genes from malaria parasites found in avian hosts of Hawaii, including the thrombospondinrelated anonymous protein (trap) gene, which encodes a protein involved in immuno-evasion and erythrocyte invasion [77]. Although trap evolves under positive selection in human malaria parasites, no evidence for positive selection was found in trap of avian malaria parasites [78]. Here, for the first time, evidence of positive selection as a driving force in the evolution and diversification of an erythrocyte invasion gene (ama-1) in avian malaria parasites is provided. These results show that $a m a-1$ is a useful nuclear marker for investigating the adaptive evolution of avian malaria parasite populations. In addition, these results suggest that the role ama-1 plays in erythrocyte invasion is evolutionarily conserved across avian Plasmodium species.

Avian Plasmodium ama-1 is relatively conserved in comparison with orthologous genes of mammalian Plasmodium species. The conservation of the hydrophobic trough in P. gallinaceum AMA1 underscores the functional importance of AMA-1 in avian Plasmodium parasites. The hydrophobic trough of AMA-1 binds to the RON complex via AMA-1-RON2 interactions [73,79]. These interactions form the invasion machinery required to mediate erythrocyte invasion [80,81]. Moreover, the identification of P. gallinaceum RON2 and the conservation of the RON2 helices involved in AMA-1 binding further supports the notion that this junction-dependent invasion process is evolutionarily conserved in avian Plasmodium parasites. Future studies will be important to investigate the signatures of selection within regions of $P$. gallinaceum RON2, and to further the understanding of junction-dependent invasion processes in avian Plasmodium parasites.

Although this process is not specific to a particular host cell type, the binding of domain III to the erythrocyte membrane protein Kx suggests that AMA-1 may be involved in host-specificity [82]. Interestingly, domain III is not well conserved in other genera belonging to Apicomplexa [82], suggesting that the functions of this 

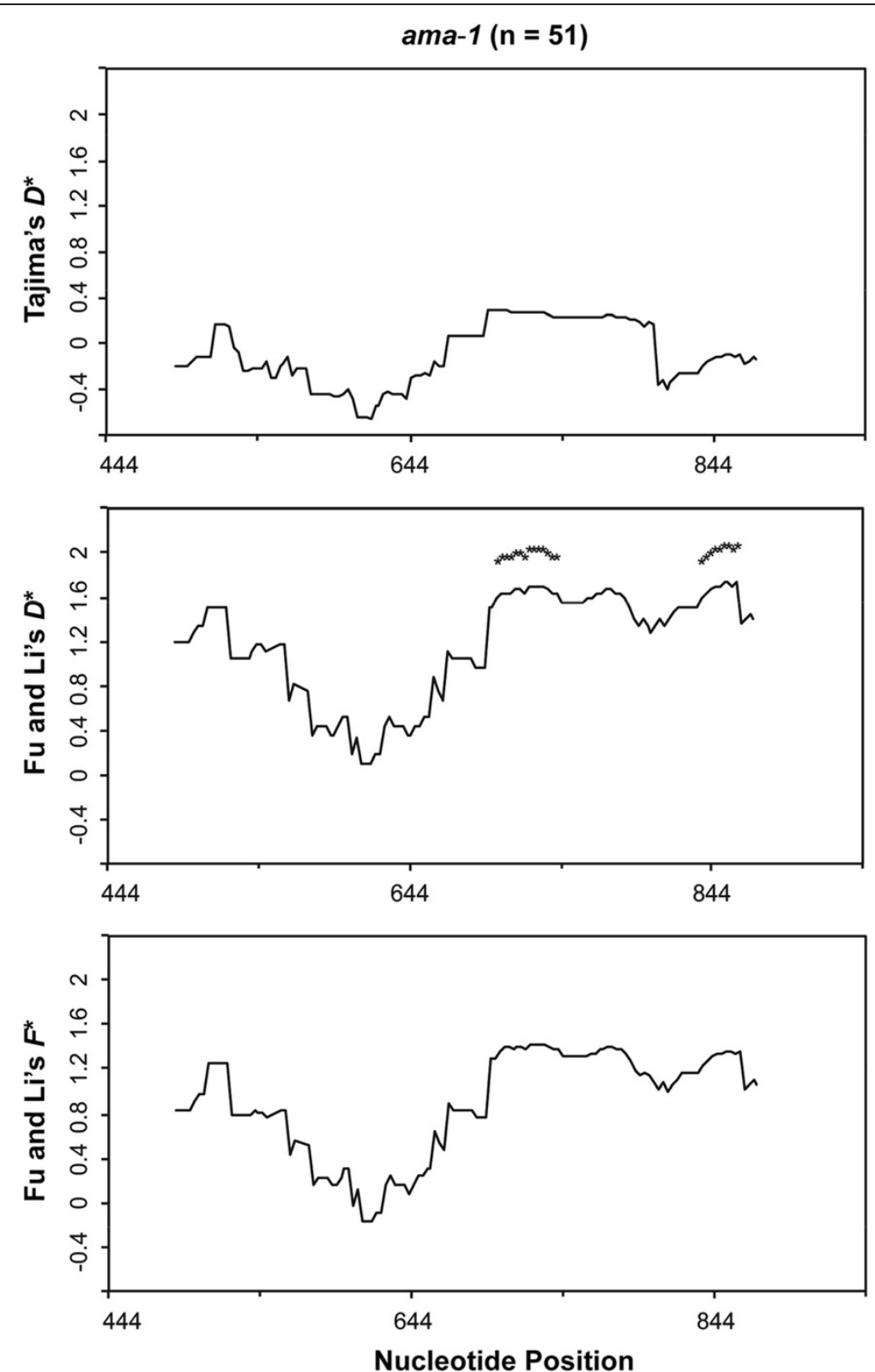

Figure 6 Sliding window plot of Tajima's $D$, Fu and Li's $D^{*}$ and $F^{*}$ tests for domain I of Plasmodium lucens ama-1. The window length is $90 \mathrm{bp}$ with a step size of $3 \mathrm{bp}$. Asterisks indicate regions where significant departure from neutrality was observed. $\mathrm{n}$ represents the number of P. lucens sequences analysed.

domain are unique to Plasmodium. More importantly, domain III of P. falciparum AMA-1 is antigenic and elicits growth-inhibiting antibodies [83]. Domain III contains two conserved immunodominant epitopes. The first conserved epitope is located at position 459-464, whereas the second is located at position 467-475. Domain III of $P$. gallinaceum AMA-1 lacks four amino acid residues within the second immunodominant epitope (between position 468-473 with respect to P. falciparum AMA-1). These differences may also be present in other avian Plasmodium species and possibly result in a lack of or escape from inhibitory antibodies directed against the second immunodominant epitope. It is thus tempting to speculate that the observed differences in the domain III region of $P$. gallinaceum AMA-1 may contribute to the diverse host range of avian Plasmodium parasites. Unfortunately, efforts to PCR amplify and assess the domain III regions in ama-1 of other avian Plasmodium parasites were unsuccessful.

In spite of this, several avian Plasmodium species exhibited genetic diversity and contained additional amino acids present within the domain I region of AMA-1. 
Plasmodium isolates from African birds contained three additional amino acids in domain I, whereas $P$. homopolare isolates from California contained two additional amino acids. Surprisingly, domain I of $P$. homopolare ama-1 was highly conserved with no genetic diversity found between 28 different isolates. One possibility for this finding is that domain I of $P$. homopolare ama-1 is subject to negative selection, as negative selection has been shown on the rhoptry-associated protein 1 (RAP-1), which is also involved in erythrocyte invasion [84]. However, this possibility is difficult to investigate considering the lack of diversity in $P$. homopolare ama-1. Alternatively, the lack of diversity may result from a recent demographic sweep (bottle-neck) or host switching events that lead to recent population expansions $[85,86]$. The latter is favoured, as $P$. homopolare was found in five different families representing nine bird species [54]. Therefore, any reciprocal selection acting on $P$. homopolare ama-1 by host protective immune responses may be weak relative to the selection imposed on a host specialist by a single host (e.g., the Olive Sunbird and P. lucens). A lack of diversity was also found in the host generalist P. megaglobularis. However, more robust sampling and sequencing of parasites is required as the true diversity may be underestimated due to low sample sizes. These results are in stark contrast to the level of genetic diversity found in P. lucens ama-1.

These findings provide significant evidence that polymorphisms in P. lucens ama-1 are maintained by positive selection. The patterns of genetic diversity across domain I of P. lucens ama-1 are consistent with studies on mammalian Plasmodium species $[72,74,87,88]$. Likewise, sliding window plots of $\pi$ and $\mathrm{Fu}$ and Li's $F^{*}$ value indicate that the region corresponding to a natural $\mathrm{T}$ cell epitope in domain I is highly polymorphic and is under positive selection in $P$. lucens ama-1, which is also in agreement with earlier studies [42,89]. This observation suggests that avian Plasmodium AMA-1 may induce T cell responses in infected bird hosts and has implications for studying immune responses in bird populations that are naturally exposed to malaria parasites. In addition, humoral immune responses against AMA-1 in bird populations may also provide valuable information for immuno-epidemiologic studies. Such studies can be particularly important for terrestrial ecosystems that are sensitive to losses in native bird populations, especially since native birds play essential roles in many terrestrial ecosystems $[90,91]$. Therefore, there is a great need to understand host-parasite interaction and its relationship to host immune responses in avian Plasmodium parasites.

\section{Conclusions}

Ultimately, these findings provide insight into the erythrocyte invasion process of avian Plasmodium, are the first evidence of host-driven selection in an avian Plasmodium species, and demonstrate the substantial applications of the $P$. gallinaceum transcriptome. The $P$. gallinaceum transcriptome dataset represents a major public genomic resource that will serve to progress research on the functional genomics and evolution of Plasmodium. Further analyses of invasion and immunoevasion-related genes could reveal additional nuclear markers for phylogenetic applications, as these genes may exhibit high levels of diversity [21]. Identifying additional markers has been difficult as the majority of sequenced Plasmodium genomes are from mammalian Plasmodium species; therefore, primer development is often facilitated using mammalian Plasmodium species sequence data and the resulting primers may not be suitable for PCR amplification of non-mammalian Plasmodium species DNA. However, with the recent sequencing and availability of the $P$. relictum transcriptome [21] and the addition of the $P$. gallinaceum transcriptome, significant progress towards adding reliable markers for more thorough phylogenetic and evolutionary studies of Plasmodium or closely related genera is expected.

\section{Additional files}

\begin{abstract}
Additional file 1: Host and parasite species locality. The table shows the source of isolates used to analyse sequence diversity.

Additional file 2: GenBank Accession numbers for the parasite taxa. GenBank Accession numbers for the parasite taxa used in this study are provided.

Additional file 3: Genbank accession numbers for the ama-1 sequences. The table shows Genbank accession numbers for the ama-1 sequences obtained from Plasmodium field isolates used in this study.

Additional file 4: Between-species divergence. The table shows between-species divergence $(K)$ calculated using Jukes and Cantor correction.
\end{abstract}

Additional file 5: Genetic distances and amino acid similarity. The table shows genetic distances computed from DNA sequences and amino acid similarity between Plasmodium gallinaceum and Plasmodium falciparum.

Additional file 6: The size distribution for Plasmodium gallinaceum transcripts. The figure shows the size distribution for Plasmodium gallinaceum transcripts that show homology to Plasmodium falciparum transcripts.

Additional file 7: Phylogenetic and MDS analysis of Plasmodium parasites. An ama-1 phylogeny and MDS analysis shows clustering of avian malaria parasites according to host species.

Additional file 8: AMA1- domain I amino acid sequence alignment. The figure shows aligned amino acid sequences with the AMA-1 domain I of Plasmodium falciparum, Plasmodium lucens, Plasmodium megaglobularis, Plasmodium globularis, Plasmodium lineage spp. PV16, and Plasmodium homopolare.

\section{Competing interests}

The authors declare that they have no competing interests.

\section{Authors' contributions}

EJL performed the RNA preparations, transcriptome analysis, ama-1 sequencing and orthologue characterization, statistical analyses, and participated in the chicken infections, blood sample collection, design of the study, and drafting of the manuscript. KSO participated in the chicken infections, blood sample 
collection and RNA preparations. LAT performed the chicken infections and assisted with the blood sample collections. KB performed the transcriptome assembly. SWR performed the characterization of the transcriptome. RNMS conceived and participated in the design of the study, and helped draft the manuscript. All authors read and approved the final version of the manuscript.

\section{Acknowledgements}

This work was supported by a National Institute of Health grant SC2Al089120-01A1, and used the Vincent J. Coates Genomics Sequencing Laboratory at UC Berkeley, supported by NIH S10 Instrumentation Grants S10RR029668 and S10RR027303. We would like to thank Dr. Robert Gwadz for kindly providing us with $P$. gallinaceum samples. We thank Eric Routman (San Francisco State University) for his assistance with statistical analysis, and thank Erika Walther and other scientists involved in sampling efforts.

\section{Author details}

'Department of Biology, San Francisco State University, San Francisco, CA 94132, USA. ²Department of Medicine and Epidemiology, School of Veterinary Medicine, University of California, Davis, CA 95616, USA

Received: 12 June 2014 Accepted: 17 September 2014 Published: 26 September 2014

\section{References}

1. Ferreira MU, da Silva Nunes M, Wunderlich G: Antigenic diversity and immune evasion by malaria parasites. Clin Diagn Lab Immunol 2004, 11:987-995.

2. Escalante AA, Lal AA, Ayala FJ: Genetic polymorphism and natural selection in the malaria parasite Plasmodium falciparum. Genetics 1998, 149:189-202.

3. Takala SL, Plowe CV: Genetic diversity and malaria vaccine design, testing, and efficacy: Preventing and overcoming "vaccine resistant malaria". Parasite Immunol 2009, 31:560-573.

4. Roy SW, Irimia M: Origins of human malaria: Rare genomic changes and full mitochondrial genomes confirm the relationship of Plasmodium falciparum to other mammalian parasites but complicate the origins of Plasmodium vivax. Mol Biol Evol 2008, 25:2511-2511.

5. Deitsch KW, Moxon ER, Wellems TE: Shared themes of antigenic variation and virulence in bacterial, protozoal, and fungal infections. Microbiol Mol Biol Rev 1997, 61:281-293.

6. Hughes AL: Circumsporozoite protein genes of malaria parasites (Plasmodium spp.): evidence for positive selection on immunogenic regions. Genetics 1991, 127:345-353.

7. Escalante AA, Grebert HM, Isea R, Goldman IF, Basco L, Magris M, Biswas S, Kariuki S, Lal AA: A study of genetic diversity in the gene encoding the circumsporozoite protein (CSP) of Plasmodium falciparum from different transmission areas-XVI. Asembo Bay Cohort Project. Mol Biochem Parasitol 2002, 125:83-90.

8. Baum J, Thomas AW, Conway DJ: Evidence for diversifying selection on erythrocyte-binding antigens of Plasmodium falciparum and P. vivax. Genetics 2003, 163:1327-1336.

9. Mayer DCG, Mu J-B, Feng X, Su X, Miller LH: Polymorphism in a Plasmodium falciparum erythrocyte-binding ligand changes its receptor specificity. J Exp Med 2002, 196:1523-1528.

10. Mayer DCG, Mu J-B, Kaneko O, Duan J, Su X, Miller LH: Polymorphism in the Plasmodium falciparum erythrocyte-binding ligand JESEBL/EBA-181 alters its receptor specificity. Proc Natl Acad Sci U S A 2004, 101:2518-2523.

11. Iyer J, Grüner AC, Rénia L, Snounou G, Preiser PR: Invasion of host cells by malaria parasites: a tale of two protein families. Mol Microbiol 2007, 65:231-249.

12. Ricklefs RE, Fallon SM: Diversification and host switching in avian malaria parasites. Proc R Soc Lond B 2002, 269:885-892.

13. Fallon SM, Bermingham E, Ricklefs RE: Host specialization and geographic localization of avian malaria parasites: a regional analysis in the Lesser Antilles. Am Nat 2005, 165:466-480.

14. Loiseau C, Harrigan RJ, Robert A, Bowie RCK, Thomassen HA, Smith TB, Sehgal RNM: Host and habitat specialization of avian malaria in Africa. Mol Ecol 2012, 21:431-441

15. Bensch S, Stjernman M, Hasselquist D, Ostman O, Hansson B, Westerdahl H, Pinheiro RT: Host specificity in avian blood parasites: a study of
Plasmodium and Haemoproteus mitochondrial DNA amplified from birds. Proc Biol Sci 2000, 267:1583-1589.

16. Ricklefs RE, Fallon SM, Bermingham E: Evolutionary relationships, cospeciation, and host switching in avian malaria parasites. Syst Biol 2004, 53:111-119.

17. Hellgren O, Pérez-Tris J, Bensch S: A jack-of-all-trades and still a master of some: prevalence and host range in avian malaria and related blood parasites. Ecology 2009, 90:2840-2849.

18. Loiseau C, Zoorob R, Robert A, Chastel O, Julliard R, Sorci G: Plasmodium relictum infection and $\mathrm{MHC}$ diversity in the house sparrow (Passer domesticus). Proc Biol Sci 2011, 278:1264-1272.

19. Sepil I, Lachish S, Hinks AE, Sheldon BC: Mhc supertypes confer both qualitative and quantitative resistance to avian malaria infections in a wild bird population. Proc Bio/ Sci 2013, 280:20130134.

20. Westerdahl H, Stjernman M, Råberg L, Lannefors M, Nilsson J-Å: MHC-I affects infection intensity but not infection status with a frequent avian malaria parasite in blue tits. PLoS One 2013, 8:e72647.

21. Hellgren $O$, Kutzer M, Bensch S, Valkiūnas $G$, Palinauskas V: Identification and characterization of the merozoite surface protein 1 (msp1) gene in a host generalist avian malaria parasite, Plasmodium relictum (lineages SGS1 and GRW4) with the use of blood transcriptome. Malar J 2013, 12:381.

22. Carter $\mathrm{R}$, Chen DH: Malaria transmission blocked by immunisation with gametes of the malaria parasite. Nature 1976, 263:57-60.

23. Gwadz RW: Successful immunization against the sexual stages of Plasmodium gallinaceum. Science 1976, 193:1150-1151.

24. Vinetz JM, Valenzuela JG, Specht CA, Aravind L, Langer RC, Ribeiro JMC, Kaslow DC: Chitinases of the avian malaria parasite Plasmodium gallinaceum, a class of enzymes necessary for parasite invasion of the mosquito midgut. J Biol Chem 2000, 275:10331-10341.

25. Li F, Patra KP, Vinetz JM: An anti-Chitinase malaria transmission-blocking single-chain antibody as an effector molecule for creating a Plasmodium falciparum-refractory mosquito. J Infect Dis 2005, 192:878-887.

26. Waters AP, Higgins DG, McCutchan TF: Plasmodium falciparum appears to have arisen as a result of lateral transfer between avian and human hosts. Proc Natl Acad Sci U S A 1991, 88:3140-3144.

27. Escalante AA, Ayala FJ: Phylogeny of the malarial genus Plasmodium, derived from rRNA gene sequences. Proc Natl Acad Sci U S A 1994 91:11373-11377.

28. Escalante AA, Ayala FJ: Evolutionary origin of Plasmodium and other Apicomplexa based on rRNA genes. Proc Natl Acad Sci U S A 1995, 92:5793-5797

29. McCutchan TF, Kissinger JC, Touray MG, Rogers MJ, Li J, Sullivan M, Braga EM, Krettli AU, Miller LH: Comparison of circumsporozoite proteins from avian and mammalian malarias: biological and phylogenetic implications. Proc Natl Acad Sci U S A 1996, 93:11889-11894.

30. Kissinger JC, Souza PCA, Soarest CO, Paul R, Wahl AM, Rathore D, McCutchan TF, Krettli AU: Molecular phylogenetic analysis of the avian malarial parasite Plasmodium (Novyella) juxtanucleare. J Parasitol 2002, 88:769-773.

31. Pick C, Ebersberger I, Spielmann T, Bruchhaus I, Burmester T: Phylogenomic analyses of malaria parasites and evolution of their exported proteins. BMC Evol Biol 2011, 11:167.

32. Nirmalan N, Wang P, Sims PFG, Hyde JE: Transcriptional analysis of genes encoding enzymes of the folate pathway in the human malaria parasite Plasmodium falciparum. Mol Microbiol 2002, 46:179-190.

33. Pornthanakasem W, Kongkasuriyachai D, Uthaipibull C, Yuthavong Y Leartsakulpanich U: Plasmodium serine hydroxymethyltransferase: indispensability and display of distinct localization. Malar J 2012, 11:387.

34. Ikadai H, Shaw Saliba K, Kanzok SM, McLean KJ, Tanaka TQ, Cao J, Williamson KC, Jacobs Lorena M: Transposon mutagenesis identifies genes essential for Plasmodium falciparum gametocytogenesis. Proc Natl Acad Sci U S A 2013, 110:E1676-E1684.

35. Deans JA, Alderson T, Thomas AW, Mitchell GH, Lennox ES, Cohen S: Rat monoclonal antibodies which inhibit the in vitro multiplication of Plasmodium knowlesi. Clin Exp Immunol 1982, 49:297-309.

36. Thomas AW, Deans JA, Mitchell GH, Alderson T, Cohen S: The Fab fragments of monoclonal lgG to a merozoite surface antigen inhibit Plasmodium knowlesi invasion of erythrocytes. Mol Biochem Parasitol 1984, 13:187-199

37. Dutta S, Haynes JD, Moch JK, Barbosa A, Lanar DE: Invasion-inhibitory antibodies inhibit proteolytic processing of apical membrane antigen 1 
of Plasmodium falciparum merozoites. Proc Natl Acad Sci U S A 2003, 100:12295-12300.

38. Deans JA, Knight AM, Jean WC, Waters AP, Cohen S, Mitchell GH: Vaccination trials in rhesus monkeys with a minor, invariant, Plasmodium knowlesi 66 kD merozoite antigen. Parasite Immunol 1988, 10:535-552.

39. Collins WE, Pye D, Crewther PE, Vandenberg KL, Galland GG, Sulzer AJ, Kemp DJ, Edwards SJ, Coppel RL, Sullivan JS: Protective immunity induced in squirrel monkeys with recombinant apical membrane antigen-1 of Plasmodium fragile. Am J Trop Med Hyg 1994, 51:711-719.

40. Xu H, Hodder AN, Yan H, Crewther PE, Anders RF, Good MF: CD4+ T cells acting independently of antibody contribute to protective immunity to Plasmodium chabaudi infection after apical membrane antigen 1 immunization. J Immunol 2000, 165:389-396.

41. Coley AM, Parisi K, Masciantonio R, Hoeck J, Casey JL, Murphy VJ, Harris KS, Batchelor AH, Anders RF, Foley M: The most polymorphic residue on Plasmodium falciparum apical membrane antigen 1 determines binding of an invasion-Inhibitory antibody. Infect Immun 2006, 74:2628-2636.

42. Escalante AA, Grebert HM, Chaiyaroj SC, Magris M, Biswas S, Nahlen BL, Lal $A A$ : Polymorphism in the gene encoding the apical membrane antigen-1 (AMA-1) of Plasmodium falciparum. X. Asembo Bay Cohort Project. Mol Biochem Parasitol 2001, 113:279-287.

43. Hodder AN, Crewther PE, Anders RF: Specificity of the protective antibody response to apical membrane antigen 1. Infect Immun 2001, 69:3286-3294.

44. Michon P, Stevens JR, Kaneko O, Adams JH: Evolutionary relationships of conserved cysteine-rich motifs in adhesive molecules of malaria parasites. Mol Biol Evol 2002, 19:1128-1142.

45. Remarque EJ, Faber BW, Kocken CHM, Thomas AW: Apical membrane antigen 1: a malaria vaccine candidate in review. Trends Parasitol 2008, 24:74-84.

46. Valkiūnas $G$, lezhova TA, Loiseau C, Smith TB, Sehgal RNM: New malaria parasites of the subgenus Novyella in African rainforest birds, with remarks on their high prevalence, classification and diagnostics. Parasitol Res 2009, 104:1061-1077.

47. Martinez C, Marzec T, Smith CD, Tell LA, Sehgal RNM: Identification and expression of maebl, an erythrocyte-binding gene, in Plasmodium gallinaceum. Parasitol Res 2013, 112:945-954.

48. Babraham Bioinformatics. [http://www.bioinformatics.babraham.ac.uk/]

49. Kent WJ: BLAT-The BLAST-Like Alignment Tool. Genome Res 2002, 12:656-664

50. Langmead B, Trapnell C, Pop M, Salzberg SL: Ultrafast and memoryefficient alignment of short DNA sequences to the human genome. Genome Biol 2009, 10:R25.

51. Grabherr MG, Haas BJ, Yassour M, Levin JZ, Thompson DA, Amit I, Adiconis X, Fan L, Raychowdhury R, Zeng Q, Chen Z, Mauceli E, Hacohen N, Gnirke A, Rhind N, di Palma F, Birren BW, Nusbaum C, Lindblad-Toh K, Friedman N, Regev A: Full-length transcriptome assembly from RNA-Seq data without a reference genome. Nat Biotechnol 2011, 29:644-652.

52. PlasmoDB: [http://plasmodb.org]

53. Valkiūnas G, lezhova TA, Loiseau C, Chasar A, Smith TB, Sehgal RNM: New species of haemosporidian parasites (Haemosporida) from African rainforest birds, with remarks on their classification. Parasitol Res 2008, 103:1213-1228.

54. Walther EL, Valkiūnas G, González AD, Matta NE, Ricklefs RE, Cornel A, Sehgal RNM: Description, molecular characterization, and patterns of distribution of a widespread New World avian malaria parasite (Haemosporida: Plasmodiidae), Plasmodium (Novyella) homopolare sp. nov. Parasitol Res 2014, 113:3319-3332.

55. Waldenström J, Bensch S, Hasselquist D, Östman Ö: A new nested polymerase chain reaction method very efficient in detecting Plasmodium and Haemoproteus infections from avian blood. J Parasitol 2004, 90:191-194.

56. Galtier N, Gouy M, Gautier C: SEAVIEW and PHYLO_WIN: two graphic tools for sequence alignment and molecular phylogeny. Comput Appl Biosci 1996, 12:543-548.

57. Maddison WP, Maddison DD: Mesquite: a modular system for evolutionary analysis. Volume Version 2.75. 2011. http://mesquiteproject.org.

58. Stamatakis A: RAxML-VI-HPC: maximum likelihood-based phylogenetic analyses with thousands of taxa and mixed models. Bioinformatics 2006, 22:2688-2690.

59. Posada D, Crandall KA: MODELTEST: testing the model of DNA substitution. Bioinformatics 1998, 14:817-818.
60. Huelsenbeck JP, Crandall KA: Phylogeny estimation and hypothesis testing using maximum likelihood. Annu Rev Ecol Syst 1997, 28:437-466.

61. Zhang Y: Template-based modeling and free modeling by I-TASSER in CASP7. Proteins 2007, 69(Suppl 8):108-117.

62. Wu S, Skolnick J, Zhang Y: Ab initio modeling of small proteins by iterative TASSER simulations. BMC Biol 2007, 5:17.

63. Wallner B, Elofsson A: Can correct protein models be identified? Protein $\mathrm{SC}$ 2003, 12:1073-1086.

64. Buchan DWA, Minneci F, Nugent TCO, Bryson K, Jones DT: Scalable web services for the PSIPRED Protein Analysis Workbench. Nucleic Acids Res 2013, 41:W349-357.

65. Egea R, Casillas S, Barbadilla A: Standard and generalized McDonaldKreitman test: a website to detect selection by comparing different classes of DNA sites. Nucleic Acids Res 2008, 36:W157-162.

66. Rozas J, Sánchez-DelBarrio JC, Messeguer X, Rozas R: DnaSP, DNA polymorphism analyses by the coalescent and other methods. Bioinformatics 2003, 19:2496-2497.

67. Tamura K, Peterson D, Peterson N, Stecher G, Nei M, Kumar S: MEGA5: molecular evolutionary genetics analysis using maximum likelihood, evolutionary distance, and maximum parsimony methods. Mol Biol Evol 2011, 28:2731-2739.

68. Tajima F: Simple methods for testing the molecular evolutionary clock hypothesis. Genetics 1993, 135:599-607.

69. Alexandre JS, Kaewthamasorn M, Yahata K, Nakazawa S, Kaneko O: Positive selection on the Plasmodium falciparum clag2 gene encoding a component of the erythrocyte binding rhoptry protein complex. Trop Med Int Health 2011, 39:77-82.

70. Fu YX, Li WH: Statistical tests of neutrality of mutations. Genetics 1993, 133:693-709.

71. Hodder AN, Crewther PE, Matthew ML, Reid GE, Moritz RL, Simpson RJ, Anders RF: The disulfide bond structure of Plasmodium apical membrane antigen-1. J Biol Chem 1996, 271:29446-29452.

72. Kocken $\mathrm{CH}$, Narum DL, Massougbodji A, Ayivi B, Dubbeld MA, van der Wel A, Conway DJ, Sanni A, Thomas AW: Molecular characterisation of Plasmodium reichenowi apical membrane antigen-1 (AMA-1), comparison with $P$. falciparum AMA-1, and antibody-mediated inhibition of red cell invasion. Mol Biochem Parasitol 2000, 109:147-156.

73. Srinivasan P, Beatty WL, Diouf A, Herrera R, Ambroggio X, Moch JK, Tyler JS, Narum DL, Pierce SK, Boothroyd JC, Haynes JD, Miller LH: Binding of Plasmodium merozoite proteins RON2 and AMA1 triggers commitment to invasion. Proc Natl Acad Sci U S A 2011, 108:13275-13280.

74. Mardani A, Keshavarz H, Heidari A, Hajjaran H, Raeisi A, Khorramizadeh MR: Genetic diversity and natural selection at the domain I of apical membrane antigen-1 (AMA-1) of Plasmodium falciparum in isolates from Iran. Exp Parasitol 2012, 130:456-462.

75. Bai T, Becker M, Gupta A, Strike P, Murphy VJ, Anders RF, Batchelor AH: Structure of AMA1 from Plasmodium falciparum reveals a clustering of polymorphisms that surround a conserved hydrophobic pocket. ProC Natl Acad Sci U S A 2005, 102:12736-12741.

76. Conway DJ: Molecular epidemiology of malaria. Clin Microbiol Rev 2007, 20:188-204.

77. Farias MEM, Atkinson CT, LaPointe DA, Jarvi SI: Analysis of the trap gene provides evidence for the role of elevation and vector abundance in the genetic diversity of Plasmodium relictum in Hawaii. Malar J 2012, 11:305.

78. Jarvi SI, Farias ME, Atkinson CT: Genetic characterization of Hawaiian isolates of Plasmodium relictum reveals mixed-genotype infections. Biol Direct 2008, 3:25.

79. Lamarque M, Besteiro S, Papoin J, Roques M, Vulliez-Le Normand B, MorlonGuyot J, Dubremetz J-F, Fauquenoy S, Tomavo S, Faber BW, Kocken CH, Thomas AW, Boulanger MJ, Bentley GA, Lebrun M: The RON2-AMA1 interaction is a critical step in moving junction-dependent invasion by Apicomplexan parasites. PLoS Pathog 2011, 7:e1001276.

80. Collins CR, Withers-Martinez C, Hackett F, Blackman MJ: An inhibitory antibody blocks interactions between components of the malarial invasion machinery. PLoS Pathog 2009, 5:e1000273.

81. Richard D, MacRaild CA, Riglar DT, Chan J-A, Foley M, Baum J, Ralph SA, Norton RS, Cowman AF: Interaction between Plasmodium falciparum apical membrane antigen 1 and the rhoptry neck protein complex defines a key step in the erythrocyte invasion process of malaria parasites. J Biol Chem 2010, 285:14815-14822. 
82. Kato K, Mayer DCG, Singh S, Reid M, Miller LH: Domain III of Plasmodium falciparum apical membrane antigen 1 binds to the erythrocyte membrane protein Kx. Proc Natl Acad Sci U S A 2005, 102:5552-5557.

83. Mueller MS, Renard A, Boato F, Vogel D, Naegeli M, Zurbriggen R, Robinson JA, Pluschke G: Induction of parasite growth-inhibitory antibodies by a virosomal formulation of a peptidomimetic of loop I from domain III of Plasmodium falciparum apical membrane antigen 1. Infect Immun 2003, 71:4749-4758.

84. Andreina Pacheco M, Ryan EM, Poe AC, Basco L, Udhayakumar V, Collins $W E$, Escalante AA: Evidence for negative selection on the gene encoding rhoptry -associated protein 1 (RAP-1) in Plasmodium spp. Infect Genet Evol 2010, 10:655-661.

85. Escalante AA, Cornejo OE, Freeland DE, Poe AC, Durrego E, Collins WE, Lal AA: A monkey's tale: The origin of Plasmodium vivax as a human malaria parasite. Proc Natl Acad Sci U S A 2005, 102:1980-1985.

86. Krief S, Escalante AA, Pacheco MA, Mugisha L, André C, Halbwax M, Fischer A, Krief JM, Kasenene JM, Crandfield M, Cornejo OE, Chavatte J-M, Lin C, Letourneur F, Grüner AC, McCutchan TF, Rénia L, Snounou G: On the diversity of malaria parasites in African Apes and the origin of Plasmodium falciparum from Bonobos. PLoS Pathog 2010, 6:e1000765.

87. Oliveira DA, Udhayakumar V, Bloland P, Shi YP, Nahlen BL, Oloo AJ, Hawley WE, Lal AA: Genetic conservation of the Plasmodium falciparum apical membrane antigen-1 (AMA-1). Mol Biochem Parasitol 1996, 76:333-336.

88. Polley SD, Conway DJ: Strong diversifying selection on domains of the Plasmodium falciparum apical membrane antigen 1 gene. Genetics 2001, 158:1505-1512.

89. Lal AA, Hughes MA, Oliveira DA, Nelson C, Bloland PB, Oloo AJ, Hawley WE, Hightower AW, Nahlen BL, Udhayakumar V: Identification of T-cell determinants in natural immune responses to the Plasmodium falciparum apical membrane antigen (AMA-1) in an adult population exposed to malaria. Infect Immun 1996, 64:1054-1059.

90. Şekercioğlu ÇH, Daily GC, Ehrlich PR: Ecosystem consequences of bird declines. Proc Natl Acad Sci U S A 2004, 101:18042-18047.

91. Tompkins DM, Gleeson DM: Relationship between avian malaria distribution and an exotic invasive mosquito in New Zealand. J Roy Soc New Zeal 2006, 36:51-62.

doi:10.1186/1475-2875-13-382

Cite this article as: Lauron et al:: Transcriptome sequencing and analysis of Plasmodium gallinaceum reveals polymorphisms and selection on the apical membrane antigen-1. Malaria Journal 2014 13:382.

\section{Submit your next manuscript to BioMed Central and take full advantage of:}

- Convenient online submission

- Thorough peer review

- No space constraints or color figure charges

- Immediate publication on acceptance

- Inclusion in PubMed, CAS, Scopus and Google Scholar

- Research which is freely available for redistribution 